\title{
Certain effects of different spectral colors on some biological parameters of the two-spotted spider mite, Tetranychus urticae
}

\author{
Manal S. M. Ismail ${ }^{1}$, Ahmed H. AboGhalia ${ }^{2}$, Maha F. M. Soliman ${ }^{2}$ and Mona \\ M.A. Ghallab ${ }^{1}$ \\ 1- Plant Protection Research Institute, Agriculture Research Center, Dokki, Cairo, \\ Egypt. \\ 2- Zoology Department, Faculty of Science, Suez Canal University, Ismailia, Egypt \\ manalsayed99@hotmail.com
}

\section{ABSTRACT}

Certain effects of different spectral light colors were studied on some biological attributes of the two-spotted spider mite, Tetranychus urticae. Rearing of animals was carried out under conditions of $27 \pm 0.5^{\circ} \mathrm{C}$; $60 \%$ R.H. and $16 \mathrm{~L} / 8 \mathrm{D}$ photoperiod on Sweet Potato leaves. Thus, 5 artificial light colors were applied under controlled laboratory conditions on these animals: blue, red, green, yellow and white Neon. After treatment, the highest number of deposited eggs/female was observed by using the blue color (14.9 \pm 0.5 eggs/female) while the lowest one was the yellow ( $3.1 \pm 0.2 \mathrm{eggs} /$ female) compared to $9.9 \pm 0.4 \mathrm{eggs} /$ female for the control group. On the other hand, diapause incidence was observed for the target females under conditions of $18 \pm 2^{\circ} \mathrm{C} ; 60 \pm 2 \%$ R.H. and the light and dark periods were set at $8 \mathrm{~L} / 16 \mathrm{D}$, respectively. Results showed that white Neon color caused the highest percentage of diapausing females $(88.66 \pm 1.8 \%)$ followed by green color $(78 \pm 3.5 \%)$, yellow $(68.66 \pm 2 \%)$, the blue color with $(54 \pm 2 \%)$, and finally none of them entered diapause under red color. Results were analyzed and discussed for the aforementioned important economic pest animals.

Keywords: Tetranychus urticae, light colors, biology, diapause incidence.

\section{INTRODUCTION}

Among the 1200 species of spider mites known in the world, the two-spotted spider mite (TSSM), Tetranychus urticae Koch, 1836 (Acari: Tetranychidae) is the most important polyphagous species (Alzoubi and Cobanoglu, 2008). It attacks over 300 host plants including vegetables (e.g., beans, eggplant, peppers, tomatoes, and potatoes), fruits (e.g., strawberries, raspberries, currants and pear) and ornamental plants (Le Goff et al., 2009). Defoliation, leaf burning, and even plant deaths can occur due to direct feeding damage. Indirect effects of feeding may include decreases in photosynthesis and transpiration and can lead to yellow-white discoloration of the leaf often referred to as bronzing, causing loss of quality and yield or the death of the host plants (Park and Lee, 2002).

The life cycle of TSSM consists of an egg, larva, protonymph, deutonymph, and adult (Walter and Proctor, 1999). All of the three active immature stages that feed on the host plant are followed by a period of quiescence called the protochrysalis, deutochrysalis, and then teliochrysalis, respectively. The larval form has only 3 pairs of legs while the proto- and deuto-nymphs each have 4. Under natural conditions, organisms are subjected to a combination of environmental factors, both biotic and abiotic. This combination ultimately determines the distribution and abundance of a 
species. Light and temperature affect the insect endocrine system, which can act as a switch that determines whether the insect averts or enters diapause (Nabeta et al., 2005) as well as the mites.

In T. urticae, the response to photoperiod has been well investigated. TSSM can overwinter as reproducing populations on host plants or in a state of diapause. Only adult females may enter a state of diapause to survive during the winter by sensing long-night conditions (Veerman, 1985), in response to decreased photoperiod and temperature, and the condition of the host plant. Once mites enter a diapause state they move from the host to hibernation sites, such as soil clods cracks in poles, and dried leaves (Masse, 1942). Diapause is terminated when temperature and photoperiod increase. Although abundant data about photoperiodism has been accumulated, other knowledge on the response to light remains limited (Suzuki et al., 2008).

By using different light emitting diodes (LEDs) color, various light colors could be formed within a single incubator to investigate the light environment that could affect TSSM population. TSSM can overwinter as reproducing populations on host plants or in a state of diapause. Only adult females may enter a state of diapause to survive during the winter by sensing long-night conditions (Veerman et al., 1985), in response to decreased photoperiod and temperature, and the condition of the host plant. Diapause is terminated when temperatures and photoperiod increase. Although abundant data about photoperiodism has been accumulated, other knowledge on the response to light remains limited (Suzuki et al., 2008).

Our research goals were to study the effect of different light colors and how it would affect the reproductive rates and behavior of TSSM, under laboratory conditions.

\section{MATERIAL AND METHODS}

\section{Rearing of two-spotted spider mite strain}

TSSM were collected from infested leaves of the Castor bean trees grown in the experimental farm of Ismailia agriculture research station. The adult females of mites were transferred with a brush to disks of Sweet Potato leaves kept on moist cotton wool pads in Petridishes for $24 \mathrm{hr}$. The deposited eggs were kept under constant temperature of $27 \pm 0.5^{\circ} \mathrm{C}, 60 \%$ R.H. and $(16 \mathrm{~L} / 8 \mathrm{D})$ photoperiod until hatching. The newly hatched larvae were then transferred to fresh leaves. Sweet potato cutting holding about 8 leaves each was placed in glass jars containing tap water which was changed every $48 \mathrm{hr}$. The sweet potato cuttings were changed twice a week in summer and weekly in winter. The colony was bred in a climatically controlled room at $27 \pm 0.5^{\circ} \mathrm{C}, 60 \%$ R.H. and $(16 \mathrm{~L} / 8 \mathrm{D})$ photoperiod for one year (Yousri, 1987).

\section{Female mite fecundity, fertility and offspring development under 5 light colors}

This was carried out according to Suzuki et al. (2007), using an incubator (MIR-152; SANYO Electric Co. Ltd., Osaka, Japan) equipped with blue, red, green, yellow, white Neon and ordinary incubator LEDs as control (Razmjou et al., 2009). Sixty adult mated females were placed on the lower surface of the Sweet Potato leaves discs ( 1 inch in diameter) and were allowed to oviposit for $24 \mathrm{hr}$ under $27 \pm 2^{\circ} \mathrm{C}, 60 \%$ R.H. and $(16 \mathrm{~L} / 8 \mathrm{D})$ photoperiod, then removed.

Single egg/disc was kept in all the Petridishes that were covered keeping a slight gap to check excessive evaporation and the cotton bed was kept wet by soaking with water twice daily so that the discs remained fresh (Hoque et al., 2008). 
The light and dark periods were set at $8 \mathrm{~L} / 16 \mathrm{D}$ at $27 \pm 2^{\circ} \mathrm{C}, 60 \%$ R.H. (Beers et al., 1998). Daily observations with a stereomicroscope were made during the incubation period till hatching of eggs (Gotoh and Gomi, 2003). All the leaf discs batches were changed with fresh discs after 3-4 days (Yousri, 1987; Martínez-villar et al., 2005). Daily observations were continued after eclosion of the larvae to determine the developmental period of immature stages up to adulthood (Naher et al., 2006; Silva et al., 2009).

Possible effect of the 5 colors light on the behavior of TSSM (Diapause incidence)

Thirty adult mated females were introduced onto a fresh Sweet Potato leaves that was placed on water-soaked cotton in a plastic Petridishes in triplicates per treatment, and they were maintained in a climatic chamber at $23 \pm 2^{\circ} \mathrm{C}, 60 \%$ R.H. for $12 \mathrm{hr}$ in continuous darkness (DD) for oviposition and then were removed. The eggs were maintained for 5 days under the same environmental conditions in darkness (Suzuki et al., 2008). The newly hatched larvae were then exposed to 5 different light colors: blue, red, green, yellow and white Neon LEDs till reaching adult stage in the incubator (MIR-152; SANYO Electric Co. Ltd., Osaka, Japan). The light and dark periods were set at $8 \mathrm{~L} / 16 \mathrm{D}$, respectively at $18 \pm 2^{\circ} \mathrm{C}$ and $60 \pm 2 \%$ R.H. (Suzuki et al., 2007). The leaf disks were renewed every 5 days and they were carefully checked once every day.

We examined the diapause status of females 7-10 days post-emergence. It was observed that $95 \%$ of females that had an orange body color did not lay any eggs at least three days following a period of 7-10 days post-maturation under the rearing conditions of the offspring; therefore they were judged to enter diapause (Goka and Takafuji, 1990; Kroon et al., 1997; Takafuji et al., 2005). Percentages of diapause induction for the 5 light colors were determined 3 weeks at $18 \pm 2^{\circ} \mathrm{C}$ after the start of the experiment, when all the mites had developed into adults (Oku et al., 2003).

Statistical analysis

All data concerning fecundity, fertility and hatchability rates were presented as arithmetic means $( \pm \mathrm{SE})$. For studying differences between groups, data were analyzed by student t-test or analysis of variance (ANOVA). All the statistical tests were performed by using the software packages SPSS 15.0.0 (USA).

\section{RESULTS AND DISCUSSION}

Egg deposition of T. urticae adult females under the influence of blue, red, green, yellow, white Neon and ordinary LED as control at $27 \pm 2^{\circ} \mathrm{C}$ is shown in Fig. (1). Results showed that TSSM exposed to blue color laid very high number of egg concentrated along the midrib.

Laid eggs were dispersed in scattered pattern on the whole leaf under red color. TSSM exposed to green color laid most of the eggs around the midrib and dispersed on the leaf. TSSM exposed to yellow color laid few eggs dispersed on the leaf. TSSM exposed to white Neon color laid few eggs dispersed on the leaf. Almost all of the eggs exposed to ordinary incubator LED as control were around the midrib, along the mid-veins and dispersed on the whole leaf in agreement with Sangeetha and Ramani (2007).

Mean numbers of deposited eggs/female $( \pm \mathrm{SE})$ (fecundity) under different light colors is shown in Table (1) and Fig. (2). Regarding the light colors effect on TSSM fecundity at $27 \pm 2^{\circ} \mathrm{C}$, the highest mean numbers of deposited eggs/females was recorded for the blue color $(14.9 \pm 0.5)$ while the lowest one was recorded for the

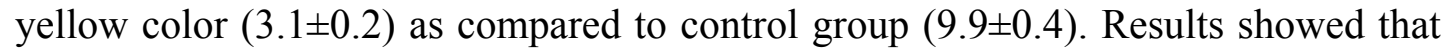


egg deposition greatly affected by the different light color especially with the blue color which caused marked increase in eggs number. Hence, light wavelengths can have a major impact on reproductive behavior and fitness of $T$. urticae.

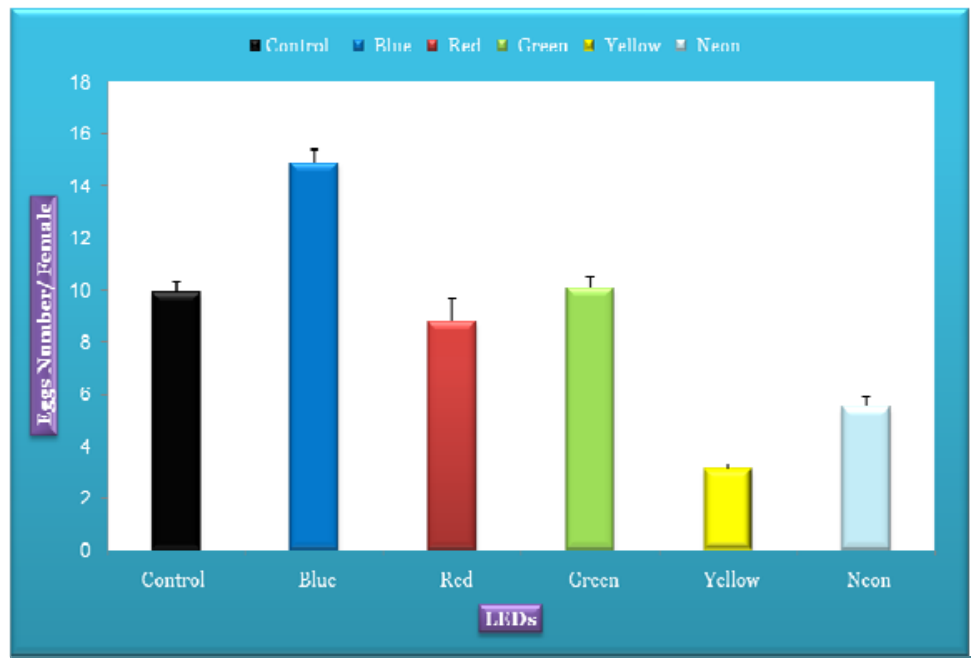

Fig. 2: Mean number of eggs/one adult female of T. urticae exposed to 5 different light colors.

Table 1: Fecundity, fertility and offspring developments of T. urticae adult females exposed to 5

\begin{tabular}{|c|c|c|c|c|c|c|c|c|}
\hline \multicolumn{3}{|c|}{ Parameters } & \multirow{2}{*}{$\begin{array}{c}\begin{array}{c}\text { Ordinary } \\
\text { LED } \\
\text { (Control) }\end{array} \\
595 \pm 21.8\end{array}$} & \multirow{2}{*}{$\begin{array}{c}\text { Blue LED } \\
895 \pm 32.8^{*}\end{array}$} & \multirow{2}{*}{$\begin{array}{l}\text { Red LED } \\
530 \pm 55.8\end{array}$} & \multirow{2}{*}{$\begin{array}{c}\begin{array}{c}\text { Green } \\
\text { LED }\end{array} \\
607 \pm 23.6\end{array}$} & \multirow{2}{*}{$\begin{array}{c}\begin{array}{c}\text { Yellow } \\
\text { LED }\end{array} \\
184 \pm 10.6^{*}\end{array}$} & \multirow{2}{*}{$\begin{array}{c}\text { White Neon } \\
\text { LED }\end{array}$} \\
\hline \multirow[t]{2}{*}{$\begin{array}{l}\text { No. of eggs } \\
\text { deposited }\end{array}$} & \multicolumn{2}{|c|}{$\begin{array}{l}\text { Mean no. of } \\
\text { eggs } / 60 \text { female }\end{array}$} & & & & & & \\
\hline & \multicolumn{2}{|c|}{$\begin{array}{l}\text { Mean no. of } \\
\text { eggs/female }\end{array}$} & $9.9 \pm 0.4$ & $14.9 \pm 0.5^{*}$ & $8.8 \pm 0.9$ & $10.1 \pm 0.4$ & $3.1 \pm 0.2^{* *}$ & $5.5 \pm 0.4^{*}$ \\
\hline \multirow{8}{*}{ 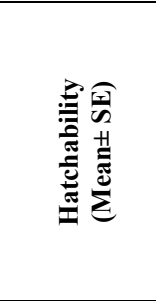 } & \multirow{2}{*}{ First Day } & No. & $43 \pm 5.3$ & $367 \pm 31.1$ & $18 \pm 1.7$ & $74 \pm 7.8$ & $85 \pm 9.5$ & $217 \pm 19.6$ \\
\hline & & $\%$ & $7.2 \pm 0.9$ & $40.9 \pm 1.9^{* * *}$ & $3.6 \pm 0.7$ & $12.2 \pm 1.2$ & $46 \pm 3.6^{* * *}$ & $65.8 \pm 1.5^{* * *}$ \\
\hline & \multirow{2}{*}{ Second Day } & No. & $416.7 \pm 16.7$ & $440 \pm 30.4$ & $261 \pm 31.8$ & $218 \pm 8.9$ & $6 \pm 1.7$ & - \\
\hline & & $\%$ & $70.1 \pm 1.5$ & $49.5 \pm 4.7^{* *}$ & $49.1 \pm 0.1^{* *}$ & $35.9 \pm 0.8^{* * *}$ & $3.2 \pm 0.8^{* * *}$ & - \\
\hline & \multirow{2}{*}{ Third Day } & No. & $117.3 \pm 12.4$ & $56 \pm 21.7$ & $239 \pm 27.2$ & $281 \pm 6.6$ & - & - \\
\hline & & $\%$ & $19.8 \pm 2.3$ & $6.1 \pm 2.2^{* *}$ & $45 \pm 0.5^{* * *}$ & $46.4 \pm 0.8^{* * *}$ & - & - \\
\hline & \multirow{2}{*}{$\begin{array}{c}\text { Hatched } \\
\text { Eggs } \\
\text { (Fertility) }\end{array}$} & No. & $577 \pm 13$ & $863 \pm 25.8$ & $518 \pm 57.3$ & $573 \pm 16.5$ & $91 \pm 11.1$ & $217 \pm 19.1$ \\
\hline & & $\%$ & $97.1 \pm 1.5$ & $96.5 \pm 0.8$ & $97.6 \pm 0.6$ & $94.5 \pm 0.9$ & $49.2 \pm 4.1^{* * *}$ & $65.8 \pm 1.5^{* * *}$ \\
\hline \multirow{2}{*}{\multicolumn{2}{|c|}{$\begin{array}{c}\text { Larvae developed to nymphs } \\
(\text { Mean } \pm \text { SE) }\end{array}$}} & No. & $565.3 \pm 13$ & $853.7 \pm 23.5$ & $506.3 \pm 60.9$ & $121.3 \pm 4.9$ & $82.7 \pm 11.5$ & \pm 18.14209 \\
\hline & & $\%$ & $97.9 \pm 0.8$ & $89.9 \pm 0.2$ & $97.5 \pm 1.1$ & $21.2 \pm 0.3^{* * *}$ & $90.5 \pm 2.4$ & $96.3 \pm 0.6$ \\
\hline \multirow{2}{*}{\multicolumn{2}{|c|}{$\begin{array}{l}\text { Nymphs developed to adults } \\
\text { (Mean } \pm \text { SE) }\end{array}$}} & No. & $545.3 \pm 10.7$ & $827.3 \pm 24.2$ & $496 \pm 55.2$ & $12.7 \pm 0.8$ & $87 \pm 10.5$ & $207 \pm 17.3$ \\
\hline & & $\%$ & $94.6 \pm 0.6$ & $95.9 \pm 0.2$ & $95.7 \pm 0.7$ & $2.2 \pm 0.2^{* * *}$ & $95.6 \pm 0.8$ & $95.63 \pm 0.9$ \\
\hline
\end{tabular}
different light colors.

$*, * * \& * * *: \mathrm{P}<0.05,<0.01 \&<0.001$ as compared to the control group.

Chadha (2008) proposed that Drosophila melanogaster adults are lightdependent organisms, light color/wavelength could affect their mating behavior. Results showed that mating behavior is not influenced by light, but likelihood of mating is influenced by light. Sperm transfer and use is not affected by light. However, it was found that flies under ultraviolet light showed an inhibition in copulation success (a result of mating behavior), yet, they showed the longest duration of copulations. In addition, strong correlations between the variables of mating behavior (mating speed, copulation duration, and fitness) were found.

Egg hatching rates and fertility of the TSSM subjected to different light colors are shown in Table (1) and Fig. (3). Egg hatching started on the $4^{\text {th }}$ day after deposition for control, blue, red, green, yellow and white Neon, respectively. The percentages of hatching were $7.2 \pm 0.9 \%, 70.1 \pm 1.5 \%$ and $19.8 \pm 2.3$ at the $1^{\text {st }}, 2^{\text {nd }}$ and $3^{\text {rd }}$ days after deposition for the control group. The percentages of hatching under 
blue color significantly differed as compared to the control being $40.9 \pm 1.9 \%$, $49.5 \pm 4.7 \%$ and $6.1 \pm 2.2 \%$ at the $1^{\text {st }}, 2^{\text {nd }}$ and $3^{\text {rd }}$ days after deposition $(\mathrm{P}<0.001)$. The percentages of hatching under red color significantly differed as compared to the control being $3.6 \pm 0.7 \%, 49.1 \pm 0.1 \%$ and $45 \pm 0.5 \%$ at the $1^{\text {st }}, 2^{\text {nd }}$ and $3^{\text {rd }}$ days after deposition $(\mathrm{P}<0.001)$.

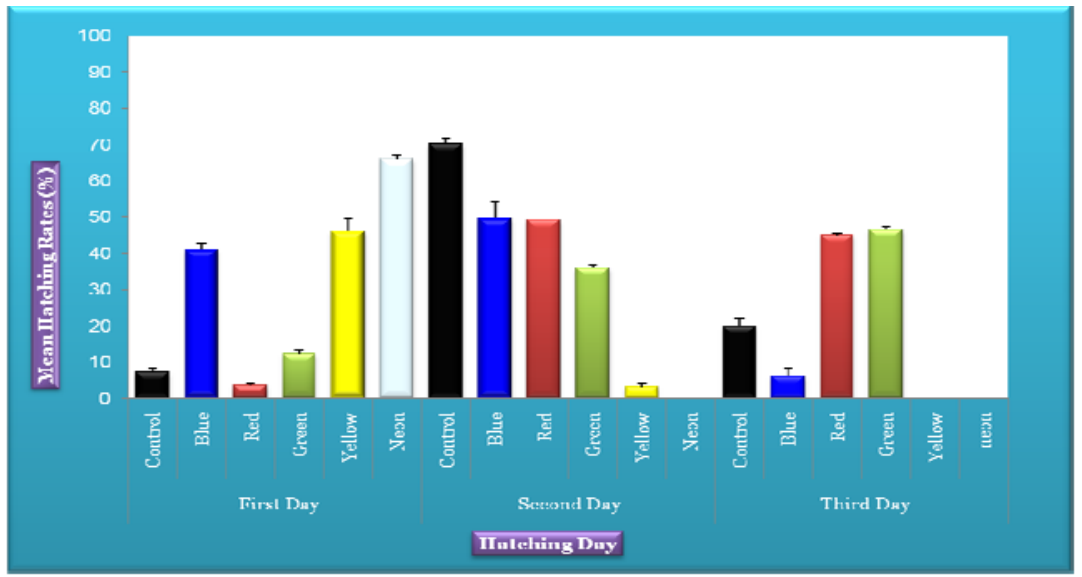

Fig. 3: Mean hatching rates (\%) of eggs oviposited by females of T. urticae exposed to 5 different light colors.

The percentages of hatching under green color significantly differed as compared to the control being $12.2 \pm 1.2 \%, 35.9 \pm 0.8 \%$ and $46.4 \pm 0.8 \%$ at the $1^{\text {st }}, 2^{\text {nd }}$ and $3^{\text {rd }}$ days after deposition $(\mathrm{P}<0.001)$. The percentages of hatching under yellow color significantly differed as compared to the control being $46 \pm 3.6 \%, 3.2 \pm 0.8 \%$ and $0 \%$ at the $1^{\text {st }}, 2^{\text {nd }}$ and $3^{\text {rd }}$ days after deposition $(\mathrm{P}<0.001)$. The percentages of hatching under white Neon color significantly differed as compared to the control being $65.8 \pm 1.5 \%, 0 \%$ and $0 \%$ at the $1^{\text {st }}, 2^{\text {nd }}$ and $3^{\text {rd }}$ days after deposition $(\mathrm{P}<0.001)$. Mean fertility rates of the TSSM were $97.1 \pm 1.5 \%, 96.5 \pm 0.8 \%$ and $97.6 \pm 0.6 \%$, $94.5 \pm 0.9 \%, 49.2 \pm 4.1 \%$ and $65.8 \pm 1.5 \%$ for control, blue, red, green, yellow and white Neon, respectively $(\mathrm{P}<0.01)$. The highest rate was recorded for the red color while the lowest rate was recorded for the yellow color.

Mean percentages of larvae developed to nymphs and mean percentage of nymphs developed to adults under different colors are shown in Table (1) and Figs. (4-5). Mean percentages of larvae developed to nymphs were $97.9 \pm 0.8 \%$, $98.9 \pm 0.2 \%, 97.5 \pm 1.1 \%, 21.2 \pm 0.3 \% 90.5 \pm 2.4 \%$ and $96.3 \pm 0.6 \%$ for control, blue, red, green, yellow and white Neon, respectively $(\mathrm{P}<0.01)$.

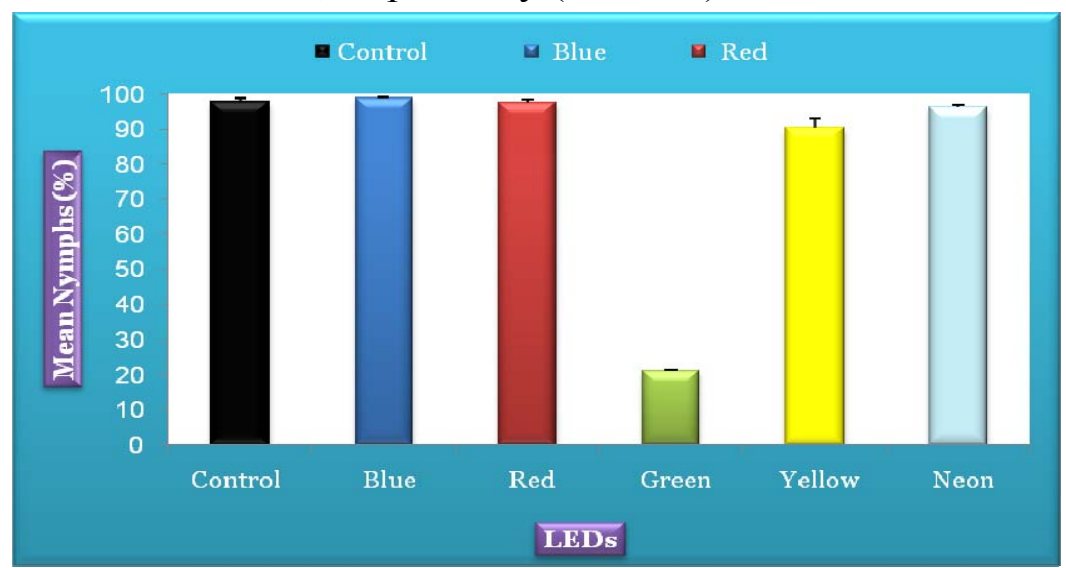

Fig. 4: Mean percentage of larvae developed to nymphs $( \pm \mathrm{SE})$ of $T$. urticae exposed to 5 different light colors. 


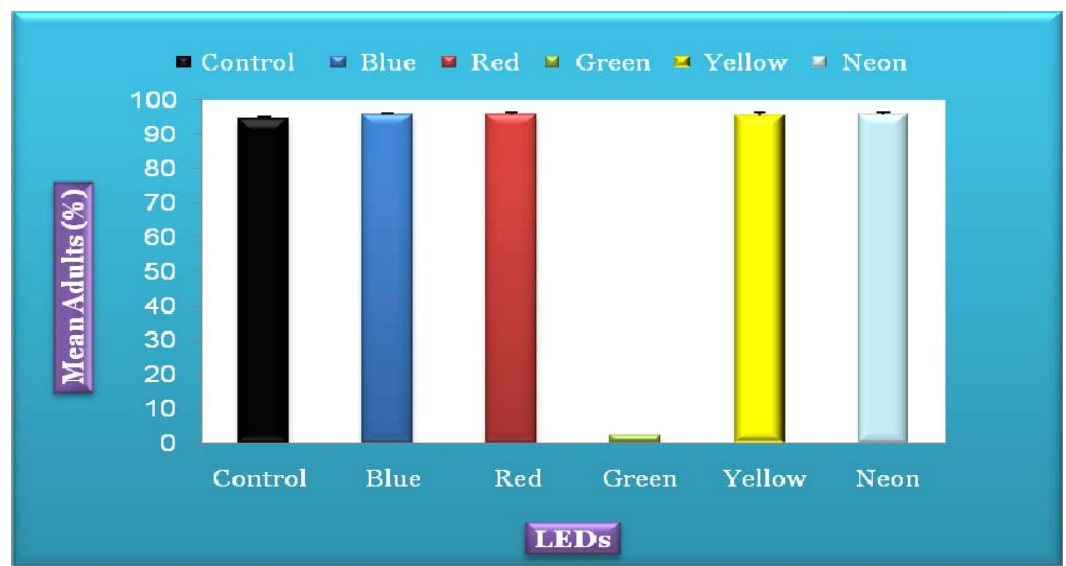

Fig. 5: Mean percentage of nymphs developed to adults $( \pm \mathrm{SE})$ of $T$. urticae exposed to 5 different light colors.

Mean percentages of nymphs developed to adults were $94.6 \pm 0.6 \%$, $95.9 \pm 0.2 \%, 95.7 \pm 0.7 \%, 2.2 \pm 0.2 \%, 95.6 \pm 0.8 \%$ and $95.63 \pm 0.9 \%$ for control, blue, red, green, yellow and white Neon, respectively $(\mathrm{P}<0.01)$. Green color significantly caused high reduction in such percentage as compared to the other colors.

Developmental periods of immature stages of TSSM in days under different colors are shown in Fig. (6). For control group, the development of egg to larval stage required 4 days. The development of larval stage to nymphal stage required 1 day. The development of nymphal stage to adult stage required 6 days. The duration till egg deposition was 2 days. Under the blue color, red color, and white Neon, the development of egg to larval stage, the development of larval stage to nymphal stage, the development of nymphal stage to adult stage required 4 days, 1 day, 6 days, respectively. Under green color, the development of egg to larval stage, the development of larval stage to nymphal stage, the development of nymphal stage to adult stage required 4 days, 1 day, 7 days, respectively. Under yellow color, the development of egg to larval stage, the development of larval stage to nymphal stage, the development of nymphal stage to adult stage required 4 days, 1 day, 5 days, respectively.

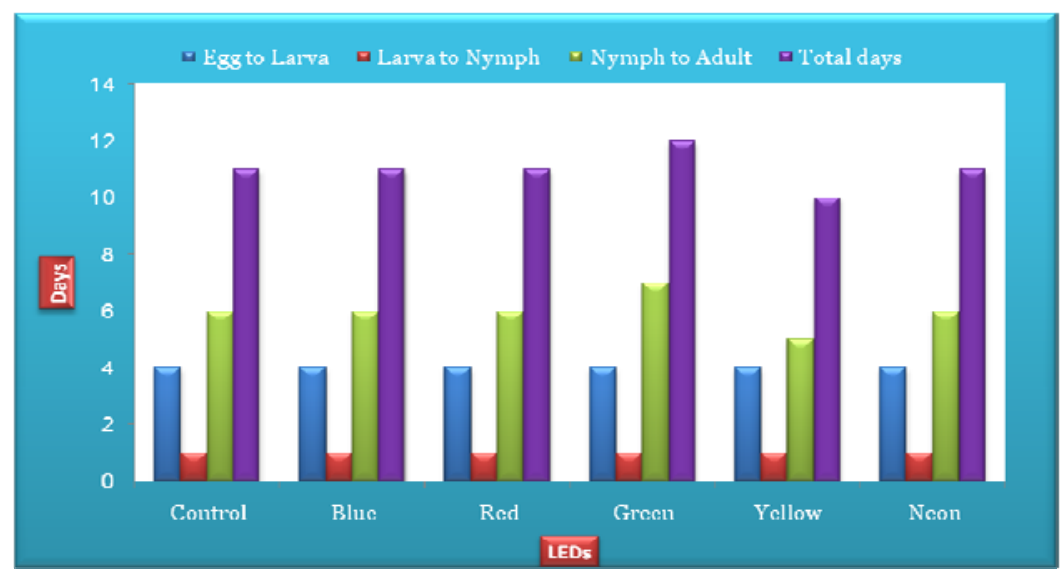

Fig. 6: Offspring development of $T$. urticae exposed to 5 different light colors.

Diapause incidence was shown in Figs. (7-8). Results show that the white Neon color caused the highest percentage of diapausing females $(88.66 \pm 1.8 \%)$ followed by the green color $(78 \pm 3.5 \%)$, then the yellow color $(68.66 \pm 2 \%)$ and the blue color with $(54 \pm 2 \%)$. On the other hand, none of them entered diapause under red-light conditions $(\mathrm{P}<0.000)$. There is abundant information on the response to 
light, particularly photoperiodism, in T. urticae. Only adult females enter diapause in order to survive during winter by sensing long night conditions, and diapausing females, which exhibit an orange body color in this period, do not feed or oviposit (Suzuki et al., 2009).

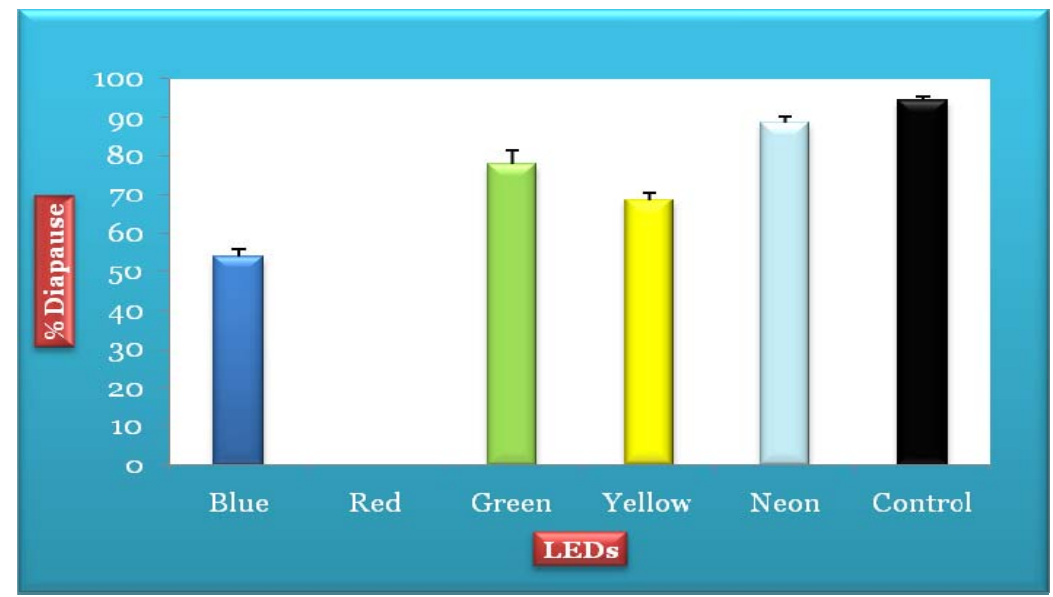

Fig. 7: Effect of light colors on diapause induction in T. urticae under (8L:16D) at $18 \pm 2^{\circ} \mathrm{C}$.
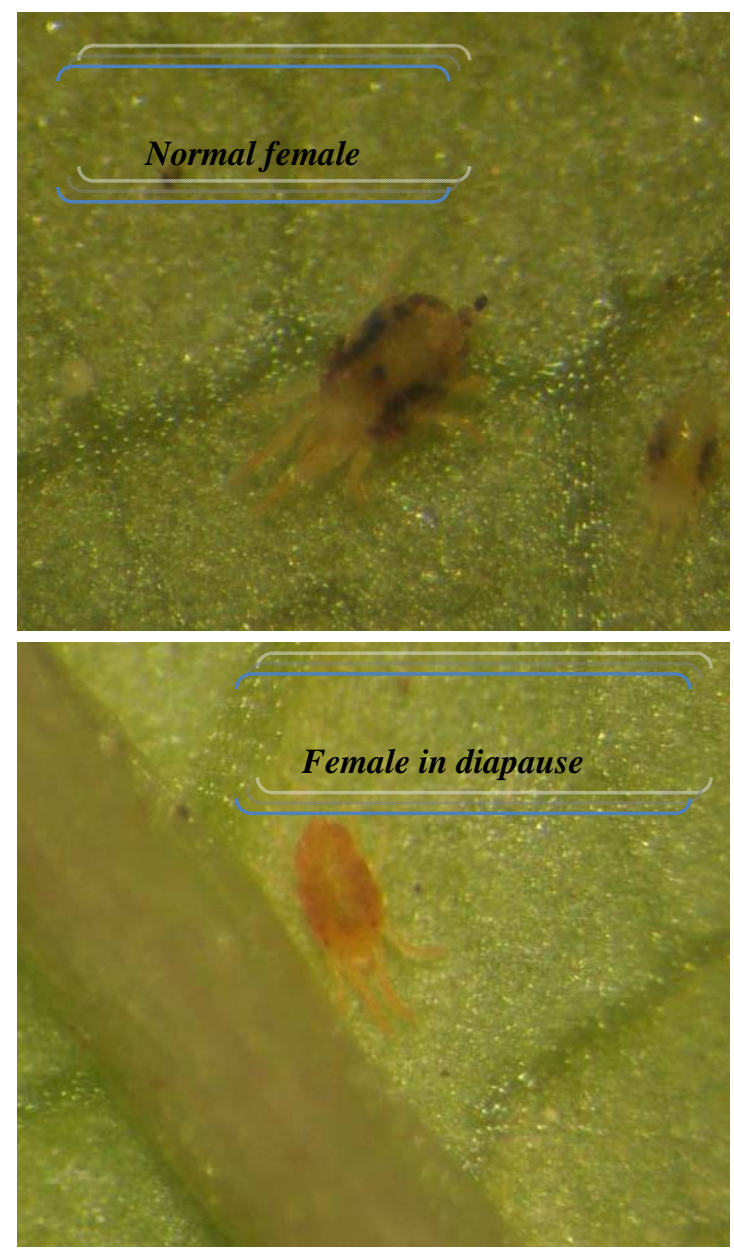

Fig. 8: Normal female T. urticae and female in diapause.

Suzuki et al. (2007) demonstrated that diapause and the delay of development in TSSM were induced by providing photoperiods which the light phase was $24 \mathrm{hr}$ or shorter with $16 \mathrm{hr}$ dark phase. Also in (2008), Suzuki et al. found that under white 
light at $2500 \mathrm{~mW} / \mathrm{m}^{2}, T$. urticae recognized the photoregimen as a long night of 16 $\mathrm{hr}$, longer than the critical night length under which all females entered diapause. On the other hand, none of them entered diapause under red-light conditions even if the intensity was as high as $2500 \mathrm{~mW} / \mathrm{m}^{2}$ and in DD. T. urticae recognized the red light as darkness, and the LD cycle was regarded as DD. They made a comparison of the diapause incidences at different light intensities under identical light qualities suggested that $T$. urticae recognized the photoperiod of blue light $(475 \mathrm{~nm})$ as a long night and nearly all females entered diapause. Under green-light conditions (572 $\mathrm{nm}$ ), diapause incidence increased with the light intensity. Under orange-light conditions $(612 \mathrm{~nm})$, diapause females appeared only at $2500 \mathrm{~mW} / \mathrm{m}^{2}$. However, $T$. urticae could not recognize this photoperiod regimen as a long night at intensities below $500 \mathrm{~mW} / \mathrm{m}^{2}$ where diapause incidences were significantly lower than at 2500 $\mathrm{mW} / \mathrm{m}^{2}$. The data suggest that the threshold intensity under blue-light conditions for $50 \%$ diapauses induction was below $50 \mathrm{~mW} / \mathrm{m}^{2}$ and threshold intensities under green- and orange-light conditions were $50-500$ and $500-2500 \mathrm{~mW} / \mathrm{m}^{2}$, respectively.

This sensitivity to red light is comparable with those of the action spectra for photoperiodic responses in Panonychus ulmi (Lees, 1953), Antheraea pernyi (Hayes, 1971), Megoura viciae (Hardie et al., 1981), and Aleyrodes proletella (Adams, 1986). Using Pectinophora gossypiella, Pittendrigh and Minis (1971) found that the eclosion rhythm and oviposition rhythm were entrained by blue light (480 nm) but not by red light $(600 \mathrm{~nm})$. However, photoperiodic induction of diapause could be controlled successfully by using wavelengths of $600 \mathrm{~nm}$ and above. This suggests that in $P$. gossypiella, different photoreceptor pigments are involved in circadian entrainment and in photoperiodism. Further, among insects and mites, there exists a photoreceptor pigment for photoperiodism, which may be coupled with a carotenoidderived chromophore but shows different sensitivity to light quality, e.g. short- and long-wave opsin. Veerman (2001) suggested that the photoperiodic clock in insects and mites most probably operates as a non-circadian hourglass with an opsin-based photoreceptor that is coupled with a carotenoid-derived chromophore, and that the circadian system plays certain roles in insect and mite photoperiodism. The evidence that the photoreceptor pigment for photoperiodism is a carotenoid-derived chromophore coupled with an opsin originated from diet manipulation (Hasegawa and Shimizu, 1988; Bosse and Veerman, 1996). On the other hand, the photoreceptor pigment for circadian entrainment might well be a vitamin B2-based cryptochrome, as demonstrated for Drosophila (Hall, 2000; Van Gelder, 2002).

Similar to our results, Suzuki et al. (2007), in a preliminary experiment, investigated the sensitivity of the photoreceptor associated with diapause induction to light quality. Exposure of juvenile TSSM to red LED light did not induce diapause $(0 \%)$ even under the short-day (LD 8:16) condition. TSSM could not sense the red light and experienced the photoperiod as continuous darkness. This is comparable to results obtained with light filters conducted with P. ulmi (Lees, 1953) and TSSM (Veerman and Veenendaal, 2003). Diapause induction was judged 7 days after adult emergence. Adult females were considered to be in diapause if their body color had changed from yellowish-green to uniform deep orange-red due to the accumulation of keto-carotenoids (Veerman, 1974). Suzuki et al. (2009) found that the orange body color of diapausing females of TSSM results from accumulation of carotenoids, a scavenger for UV-induced reactive oxygen species. This may explain the low mortality of diapausing females. Diapausing females may overcome the deleterious effects of UV-B during winter in the absence of leaves by emigrating to UV-free environments and by accumulating carotenoids. 
In conclusion, using bleu light is recommended for experimental rearing of TSSM as it yields a large number of eggs. Yellow light is also recommended in field application as it can control TSSM by causing great reduction in egg numbers.

\section{REFERENCES}

Adams, A.J. (1986): Night-interruption experiments and action spectra for dawn and dusk in relation to the photoperiodic clock of the cabbage whitefly, Aleyrodes proletella (Homoptera: Aleyrodidae). J. Insect. Physiol., 32: 71-78.

Alzoubi, S. and Cobanoglu, S. (2008): Toxicity of some pesticides against Tetranychus urticae Koch and its predatory mites under laboratory conditions. American-Eurasian J. Agric. Environm. Sci., 3(1): 30-37.

Beers, E.H.; Riedl, H. and Dunley, J.E. (1998): Resistance to abamectin and reversion to susceptibility to fenbutatin oxide in spider mite (Acari: Tetranychidae) populations in the Pacific Northwest. J. Econ. Entomol., 91: 352-360.

Bosse, T.H.C. and Veerman, A. (1996): Involvement of vitamin A in the photoperiodic induction of diapause in the spider mite Tetranychus urticae is demonstrated by rearing an albino mutant on a semi-synthetic diet with and without b-carotene or vitamin A. Physiol. Entomol., 21: 188-192.

Chadha, A.K. (2008): The Effect of Light Wavelength on Mating, Copulation \& Fitness in Drosophila melanogaster. Enquiries J. Interdisciplinary Studies for High School Students, 3(1): 1-8.

Goka, K. and Takafuji, A. (1990): Genetical studies on the diapause of the twospotted spider mite, Tetranychus urticae Koch. Appl. Entomol. Zool., 25: 119125.

Gotoh, T. and Gomi, K. (2003): Life-history traits of the kanzawa spider mite Tetranychus kanzawai (Acari: Tetranychidae). Appl. Entomol. Zool., 38 (1): 7-14.

Hall, J.C. (2000): Cryptochromes: sensory reception, transduction, and clock functions subserving circadian systems. Curr. Opin. Neurobiol. 10: 456-466.

Hardie, J., Lees, A.D. and Young, S. (1981): Light transmission through the head capsule of an aphid, Megoura viciae. J. Insect. Physiol., 27: 773-777.

Hasegawa, K. and Shimizu, I. (1988): Occurrence of retinal and 3-hydroxy-retinal in a possible photoreceptor of the silkworm brain involved in photoperiodism. Experientia, 44: 74-76.

Hayes, D.K. (1971): Action spectra for breaking diapause and action spectra of insect brain tissue. In: Biochronometry (M. Menaker ed.). National Academy of Sciences, Washington DC, pp.: 392-402.

Hoque, M.F., Islam, W. and Khalequzzaman, M. (2008): Life tables of two-spotted spider mite Tetranychus urticae Koch (Acari: Tetranychidae) and its predator Phytoseiulus Persimilis Athias-Henriot (Acari: Phytoseiidae). J. Bio. Sci., 16: $1-10$.

Kroon A., Veenendaal, R.L. and Veerman, A. (1997): Photoperiodic induction of diapause in the spider mite Tetranychus urticae: qualitative or quantitative time measurement? Physiol. Entomol., 22: 357-364.

Le Goff, G., Mailleux, A.C., Detrain, C., Deneubourg, J.L., Clotuche, G. and Hance, T. (2009): Spatial distribution and inbreeding in Tetranychus urticae. Biologies, 332: 927-933. 
Lees, A.D. (1953): Environmental factors controlling the evocation and termination of diapause in the fruit tree red spider mite Metatetranychus ulmi Koch (Acarina: Tetranychidae). Ann. Appl. Biol., 40: 449-486.

Martínez-villar, E., Sáenz-de-cabezón, F.J., Moreno-grijalba, F., Marco, V. and Pérezmoreno, I. (2005): Effects of azadirachtin on the two-spotted spider mite, Tetranychus urticae (Acari: Tetranychidae). Exp. Appl. Acarol., 35: 215-222.

Masse, A.M. (1942): Some important pests of the hop. Ann. appl. Biol., 29: 324-326.

Nabeta, F.H., Nakai, M. and Kunimi, Y. (2005): Effects of temperature and photoperiod on the development and reproduction of Adoxophyes honmai (Lepidoptera: Tortricidae). Appl. Entomol. Zool., 40(2): 231-238.

Naher, N., Islam, T., Haque, M.M. and Parween, S. (2006): Effects of native plants and IGRs on the development of Tetranychus urticae Koch (Acari: Tetranychidae). Univ. J. Zool. Rajshahi Univ., 25: 19-22.

Oku, K., Yano, S. and Takafuji, A. (2003): Different maternal effects on diapause induction of tetranychid mites, Tetranychus urticae and T. kanzawai (Acari: Tetranychidae). Appl. Entomol. Zool., 38(2): 267-270.

Park, Y.L. and Lee, J.H. (2002): Leaf cell and tissue damage of cucumber caused by two-spotted spider mite (Acari: Tetranychidae). J. Econ. Entomol., 95: 952957.

Pittendrigh, C.S. and Minis, D.H. (1971): The photoperiodic time measurement in Pectinophora gossypiella and its relation to the circadian system in that species. In: Biochronometry (M. Menaker ed.). National Academy of Sciences, Washington DC, pp.: 212-250.

Razmjou, J., Tavakkoli, H. and Nemati, M. (2009): Life history traits of Tetranychus urticae Koch on three legumes (Acari: Tetranychidae). Mun. Ent. Zool., 4(1): 204-211.

Sangeetha, G.K. and Ramani, N. (2007): Biological studies of Tetranychus neocaledonicus Andre (Acari: Tetranychidae) infesting Moringa oleifera Lam. Bull. P. Appl. Sci., 26A (2): 51-57.

Silva, E.A., Reis, P.R., Carvalho, T.M.B. and Altoé, B.F. (2009): Tetranychus urticae (Acari: Tetranychidae) on Gerbera jamesonii Bolus and Hook (Asteraceae). Braz. J. Biol., 69(4): 1121-1125.

Suzuki, T., Amano, H., Goto, E., Takeda, M. and Kozai, T. (2007): Effects of extending the light phase on diapause induction in a Japanese population of the two-spotted spider mite, Tetranychus urticae. Exp. Appl. Acarol., 42: 131138.

Suzuki, T., Fukunaga, Y., Amano, H., Takeda, M. and Goto, E. (2008): Effects of light quality and intensity on diapause induction in the two-spotted spider mite, Tetranychus urticae. Appl. Entomol. Zool., 43(2): 213-218.

Suzuki, T., Watanabe, M. and Takeda, M. (2009): UV tolerance in the two-spotted spider mite, Tetranychus urticae. J. Ins. Physiol., 55: 649-654.

Takafuji, A., Hinomoto, N., Shih, C.T., Gotoh, T., Ho, C. and Wang, C. (2005): Diapause characteristics of the Taiwanese populations of Tetranychus kanzawai Kishida and T. urticae Koch (Acari: Tetranychidae). P. Prot. Bull., 47: 103-114.

Van Gelder, R.N. (2002): Tales from the crypt (ochromes). J. Biol. Rhythms., 17: 110-120.

Veerman, A. (1974): Carotenoid metabolism in Tetranychus urticae Koch (Acari: Tetranychidae). Comparative biochemistry and physiology part B: Comparative Biochemistry, 47: 101-116. 
Veerman, A. (1985): Diapause. In: Helle W, Sabelis MW (eds) Spider mites: Their biology, natural enemies and control. Elsevier, Amsterdam, 1(A).

Veerman, A. (2001): Photoperiodic time measurement in insects and mites: a critical evaluation of the oscillator-clock hypothesis. J. Insect. Physiol., 47: 10971109.

Veerman, A. and Veenendaal, R.L. (2003): Experimental evidence for a non-clock role of the circadian system in spider mite photoperiodism. J. Insect. Physiol,, 49: 727-732.

Veerman, A.; Slagt, M.E.; Alderlieste, M. F. J. and Veenendaal, R. L. (1985): Photoperiodic induction of diapause in an insect is vitamin A dependent. Experientia, 41: 1194-1195.

Walter, D. E. and Proctor, H. C. (1999): Mites: ecology, evolution and behavior. University of New South Wales (UNSW) Press, Sydney and CABI publishing, Wallingford, pp. 322.

Yousri, H. (1987): Toxicological studies on certain acaricides. Ph.D. Thesis, Fac. of Agric., Zagazig Univ., pp: 220. 

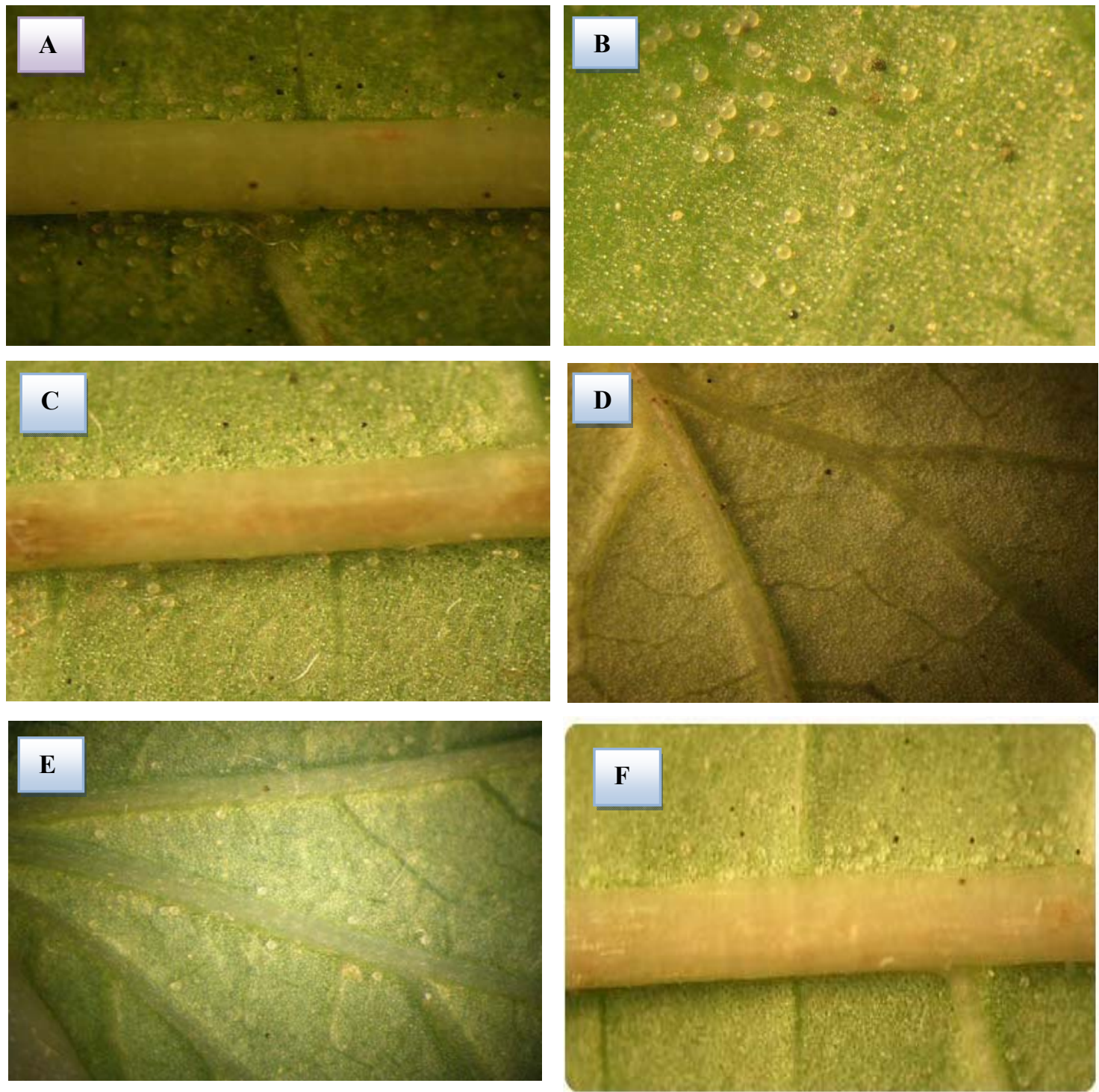

Fig. 1: Egg deposition of T. urticae adult females under the influence of: (A) blue LED, (B) red LED, (C) green LED, (D) yellow LED, (E) white Neon LED and (F) ordinary LED as control at $27 \pm 2^{\circ} \mathrm{C}$. 


\section{ARABIC SUMMARY}

بعض تأثيرات ألوان الطيف المختلفة علي معايير بيولوجية متنوعة للأكاروس العنكبوتي ذو البقعتين تترانيكس يورتيكا

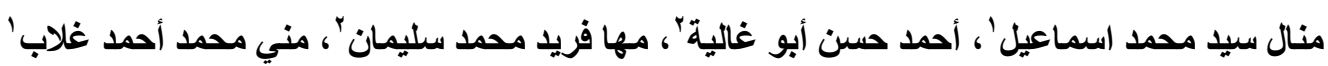

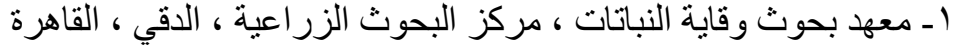

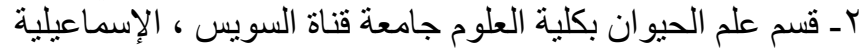

تمت دراسة بعض العوامل البيولوجية من حيث تأثير استعمال أضواء صناعية ملونة علي الأكاروس

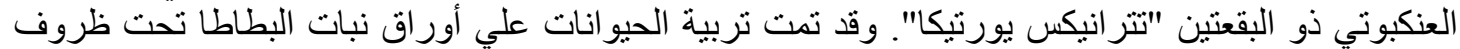

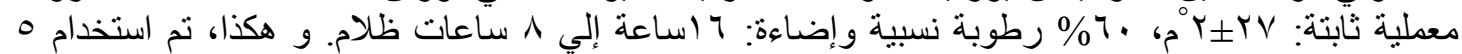

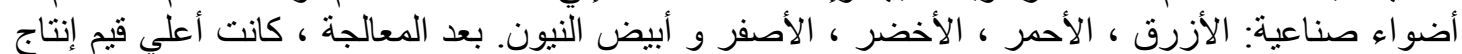

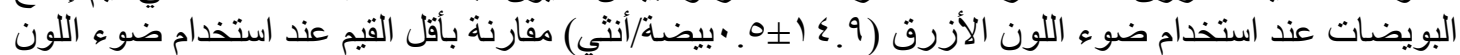

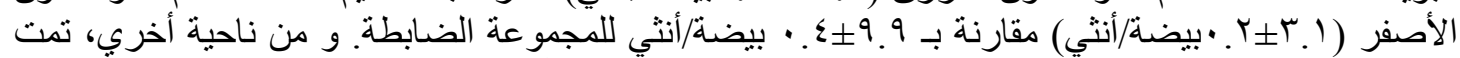

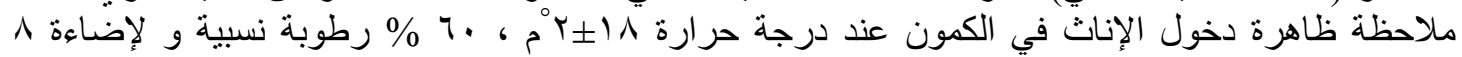

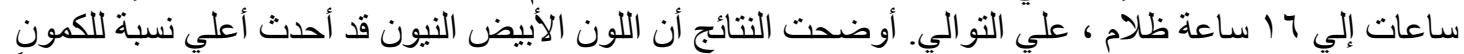

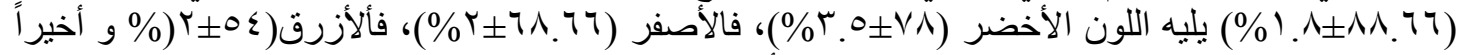

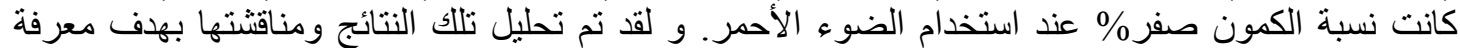
أعمق عن تللك الحيو انات ذات الأهمية الإقتصادية. 